\title{
O Ensino de Química integrado a temas ambientais: Um relato de experiência com escolares do ensino médio
}

Chemistry Teaching integrated with environmental themes: An experience report with high school students

Enseñanza de la Química integrada con temas ambientales: Un relato de experiencia con estudiantes de secundaria

Francisco Espedito Diniz ORCID: https://orcid.org/0000-0001-5969-5714 Instituto Federal do Rio Grande do Norte, Brasil E-mail: fc_francisco@outlook.com

Clécio Danilo Dias da Silva ORCID: https://orcid.org/0000-0002-7776-8830 Universidade Federal do Rio Grande do Norte, Brasil E-mail: danilodiass18@gmail.com

Oberto Grangeiro da Silva ORCID: https://orcid.org/0000-0002-1268-0774 Instituto Federal do Rio Grande do Norte, Brasil E-mail: oberto.silva@ifrn.edu.br

Daniele Bezerra dos Santos ORCID: http://orcid.org/0000-0001-7896-6946 Instituto Federal do Rio Grande do Norte, Brasil E-mail: Daniele.bezerra@ifrn.edu.br

\begin{abstract}
Resumo
Esse trabalho teve como objetivo relatar uma experiência envolvendo a aplicação de uma Sequência Didática (SD) integrando conteúdos de química à temas ambientais para estudantes do ensino médio (EM). As atividades foram realizadas em uma escola pública, localizada na Cidade de Encanto, região do Alto Oeste, no Estado do Rio Grande do Norte, junto aos estudantes matriculados na $3^{\mathrm{a}}$ série do EM. Visando proporcionar uma efetiva e satisfatória em funções orgânicas e suas relações com o meio ambiente, estruturou-se uma sequência didática em 05 etapas: I) Sondagem dos conhecimentos prévios dos estudantes; II); Aula de campo no Rio encanto; III) Aulas expositivas-dialógicas abordando conteúdos de Química e meio ambiente; IV) Elaboração de cartazes educativos-ambientais; V) Socialização dos materiais elaborados. Por meio desta experiência vivenciada, acredita-se que a inserção de temas ambientais associadas às aulas de Química, possibilitam que os discentes sejam sensibilizados quanto as questões ambientais locais, tornandose assim, cidadãos críticos e conscientes, intervindo no meio social de sua vivência com práticas socioambientalmente, inovadoras, transformadoras e sustentáveis.
\end{abstract}

Palavras-chave: Sequência didática; Ensino de Química; Temas ambientais; Educação básica.

\begin{abstract}
This work aimed to report an experience involving the application of a Didactic Sequence (DS) integrating chemistry contents to environmental themes for High School Students (HSS). The activities were developed in a public school, located in Encanto City, High West' region, in the State of Rio Grande do Norte, with students enrolled in the 3rd grade of HSS. Aiming to provide an effective and satisfactory in organic functions' contents and their relationship with the environment, the didactic sequence was structured in 05 steps: I) Survey of students' prior knowledge; II); Field lesson in Encanto' River; III) Expositive-dialogical classes addressing contents of chemistry and the environment; IV) Elaboration of educational-environmental posters; V) Socialization of elaborated materials. Through this lived experience, it is believed that the inclusion of environmental themes associated with Chemistry classes, allows students to be sensitized to local environmental issues, thus becoming critical and conscientious citizens, intervening in the social environment of their experience with social and environmental practices, innovative, transforming and sustainable.
\end{abstract}

Keywords: Didactic sequence; Chemistry Teaching; Environmental themes; Basic education.

\section{Resumen}

El objetivo de este trabajo fue reportar una experiencia de aplicación de una Secuencia Didáctica (SD) integrando contenidos de química a temas ambientales para estudiantes de secundaria (ES). Las actividades se desarrollaron en una escuela pública, ubicada en la Ciudad de Encanto, Región Alto Oeste, en el Estado de Rio Grande do Norte, con estudiantes matriculados en el 3er grado de ES. Para brindar un desempeño efectivo y satisfactorio en las funciones 
orgánicas y en su relación con el medio, se estructuró una secuencia didáctica en 5 etapas: I) Encuesta de conocimientos previos de los estudiantes; II); Clase de campo en Rio do Encanto; III) Clases expositivo-dialógicas que abordan contenidos de Química y medio ambiente; IV) Elaboración de carteles educativos-ambientales; V) Socialización de materiales elaborados. A través de esta experiencia, se cree que la inclusión de temas ambientales asociados a las clases de Química permite que los estudiantes tomen conciencia de los problemas ambientales locales, convirtiéndose así en ciudadanos críticos y conscientes, interviniendo en el entorno social de su experiencia. innovador, transformador y sostenible.

Palabras clave: Secuencia didáctica; Enseñanza de la Química; Temas ambientales; Educación básica.

\section{Introdução}

Os conteúdos de química estão presentes em diversas atividades da sociedade, desde a produção e o consumo constante de produtos químicos, como também na geração de resíduos e impactos ambientais, cuja influência afeta direta ou indiretamente o meio ambiente, na qualidade de vida dos seres vivos e nas tomadas de decisões do cidadão, por isso, ela se torna fundamental na formação da cidadania (Santos, 2011; Santos, 2020).

Durante o processo educacional de formação dos sujeitos, especialmente nas disciplinas das Ciências Naturais (Química, Física e Biologia), apesar da busca constante pela superação do ensino tradicional e reducionista (Moura-Figueira \& Rocha, 2016; Castro; Paiva \& Silva, 2019), muitos docentes ainda utilizam metodologias tradicionais de ensino, marcadas pela processo de transmissão-recepção (Lopes et al., 2011), geralmente centrados no professor, cujos conteúdos trabalhados são apresentados de forma fragmentada e que, de maneira semelhante, a compreensão desses conteúdos chegam aos alunos de forma rotulada pelas disciplinas, o que torna o processo de ensino e aprendizagem desinteressante e, o aluno, se sente desmotivado para participar deste processo. Essa metodologia tradicional de ensino ou da "educação bancária", conforme caracterizada por Paulo Freire (2014), na obra Pedagogia do Oprimido, refere-se a um processo em que "o educador é o que sabe, o que pensa/diz e que são o sujeito do processo", enquanto que, os educandos, "são os que não sabem, os que apenas escutam e que são meros objetos do processo".

Aliado aos fatores acima citados, a avaliação educacional é um outro problema evidente. No Brasil, o sistema avaliativo tradicional favorece a continuação desse modelo e ainda força o aluno a não assimilação e apropriação do conhecimento, mas sim a um mecanismo de memorização (dos conceitos, fórmulas, etc.), para serem transcritos em provas escritas que, geralmente, serve apenas para aprovar ou reprovar (Galvão, 2013) e que, apesar da atual diversidade de métodos e instrumentos avaliativos, geralmente os docentes utilizam o mesmo método avaliativo para diferentes sujeitos, não respeitando as individualidades (Hoffman, 2011). Apesar do método tradicional de ensino estar enraizado na prática docente, ainda é um grande desafio para nós, educadores, a elaboração e a aplicação permanente de ações educativas práticas e reflexivas que privilegiem os conhecimentos prévios dos estudantes e que promovam a pesquisa de campo e em grupo, oportunizando um ambiente investigativo de aprendizagem, através do diagnóstico in loco de problemas, da descrição de informações pertinentes, surgimento de dúvidas, construção de hipóteses, experimentações e correlações com os conteúdos.

Nesse contexto, o ensino de Química exerce um papel de grande relevância na formação de crianças, jovens e adultos, não unicamente como transmissora de conhecimentos sistematizados, mas para a contribuição para a formação crítica do cidadão, através de um trabalho responsável, sensível, contextualizado e crítico, possibilitando preparar o indivíduo tanto para desenvolver suas competências e habilidades, como para viver em sociedade. Para Nascimento, Ricarte e Ribeiro (2007), especificamente para os conteúdos da química orgânica, os autores afirmam que eles são de grande importante para a construção do conhecimento, tanto dentro e quanto fora de sala de aula. No entanto, Rodrigues et al. (2018), registram que este componente curricular se encontra descontextualizado da realidade do aluno e por possuir um ensino puramente teórico.

Uma das formas de oportunizar momentos e ambientes que promovam a aprendizagem, são as metodologias que visem assegurar a contextualização dos conteúdos com situações do dia a dia dos estudantes (Lima et al., 2019), possibilitando que 
estes sujeitos sejam capazes de diagnósticas situações e problemas do seu dia a dia, discutir e debater questões cientificas que permeiam a comunidade de forma reflexiva, crítica e consciente de seu papel enquanto cidadão, além da análise e proposição de resolução dos problemas emergentes do seu contexto social.

Segundo Wartha e Alário (2005) a contextualização significa construir significados e que estes significados não são neutros. Para os autores, os sujeitos incorporam significados valores porque explicitam o seu cotidiano e constroem a sua compreensão dos problemas do entorno social e cultural e facilitam o processo da descoberta e ressignificação. Buscar o significado do conhecimento a partir de contextos do mundo ou da sociedade em geral é levar o aluno a compreender a relevância e aplicar o conhecimento para entender os fatos, tendências, fenômenos, processos que o cercam.

Atualmente, uma vez que o debate científico, cultural e político sobre o meio ambiente vêm ganhando espaço na sociedade brasileira, especialmente nos últimos anos devido a inúmeros problemas causados pela sociedade e pela má gestão dos recursos naturais, integrar esta temática junto às demandas do Ensino de Ciências na atualidade apresenta-se como um novo desafio e novas possibilidades para a formação de sujeitos críticos e reflexivos, aptos a reconhecer-se como ser integrante do meio ambiente e a interagir com o conhecimento científico e com outros saberes. De acordo com Latini e Sousa (2011), apesar de todas as recomendações para um ensino de Ciências em interlocução com a educação ambiental, na prática o que se verifica nas instituições de educação básica são atividades pontuais e desconectadas da realidade vivida pelos alunos (Arrigo; Alexandre \& Assai, 2018), além de uma organização curricular que possibilita a fragmentação do conhecimento e, no tocante à prática docente, são dificuldades são apontadas para poder superar de tais questões.

No Brasil, apesar da consolidação da Política Nacional do Meio Ambiente, Lei 6.938/1981, na Constituição Federal do Brasil de 1988, e da Política Nacional de Educação Ambiental, Lei 9.795/1999 e das Diretrizes Curriculares Nacionais para Educação Ambiental (DCNEA), Resolução no 2 de 15 de junho de 2012, Parecer CNE/CP nº 14/2012. As DCNEA (2012) (Brasil, 2012), reafirmarem que a Educação Ambiental (EA) é componente integrante, essencial e permanente da Educação Nacional, devendo estar presente, de forma articulada, nos níveis e modalidades da Educação Básica e Superior. No ensino das Ciências, em especial no Ensino de Química, diversos trabalhos defendem uma mudança radical para o ensino, de forma que a desenvolver uma educação voltada para a cidadania e capacidade de tomada de decisão, a partir de trabalhos que articule o conhecimento químico de forma problematizada ao contexto social dos discentes (Freire, 2014; Arrigo \& Alexandre; Assai, 2018) e nas ações educativas-ambientais (Latini \& Sousa, 2011; Silva et al., 2015; Morais \& Silveira, 2016; Diniz et al., 2020; Santos, 2020, Diniz et al., 2021) como estratégias para facilitar e integrar a aprendizagem dos conteúdos às questões ambientais.

Diante desta problemática, trabalhos nos últimos anos evidenciam uma preocupação especial no ensino de Química no que diz respeito às proposições de estratégias e recursos que auxiliem os estudantes na construção do seu próprio conhecimento (Pazinato \& Braibante, 2014; Diniz et al., 2020; Diniz et al., 2021). Para Ribeiro-Junior (2015) e Souza e Souza (2014) o professor assume um importante papel neste processo de integração de saberes, uma vez que ele será o responsável por buscar e selecionar informações contextualizadas e atuais, como também de selecionais abordagens metodológicas e recursos didáticos que serão utilizados no processo do desenvolvimento de competências e habilidades para estimular o compartilhamento de saberes entre os sujeitos, estímulo a curiosidade e educação científica nos alunos, através da introdução de problemáticas e abordando contextos próximos da realidade cotidiana dos alunos.

Uma das estratégias para integrar a aprendizagem dos conteúdos de química aos temas ambientais é o estabelecimento de sequencias didáticas que oportunizem momentos organizados de ensino e de aprendizagem. As Sequências Didáticas (SD) são definidas por Zabala (1998) como estratégias utilizadas desde 1970 e que se apresentam como um conjunto de estratégias e atividades que são ordenadas, estruturadas e articuladas, de forma que sejam propostos objetivos educacionais, cujo princípio é atingir a aprendizagem dos alunos. Na perspectiva teórica apresentada por Méheut (2005), as SD são uma ferramenta importante 
que pode unificar o ensino a pesquisa, como o conjunto de atividades relacionadas entre si, organizadas e planejadas para ensinar e pesquisar sobre um determinado conteúdo.

Diante das discussões realizadas, faz-se necessário questionar: "quais as contribuições que uma sequência didática (SD) envolvendo temas de química e meio ambiente podem trazer para a aprendizagem dos estudantes?”. Neste sentido, o presente trabalho teve como objetivo relatar uma experiência envolvendo a aplicação de uma SD integrando conteúdos de química à temas ambientais para estudantes do ensino médio.

\section{Metodologia}

Esta é uma pesquisa de caráter qualitativo, por meio da Observação Participante (OP) da realidade, possui caráter descritivo e se preocupa mais com o processo do que com o produto. É uma pesquisa qualitativa (Oliveira, 2016) que se enquadra na modalidade de pesquisa descritiva, segundo Gil (2002), pois tem o objetivo de entender e descrever os fenômenos para compreendê-lo de diversas formas (Angrosino, 2009). No que diz respeito a OP, Queiroz et al. (2007) afirma que ela se constitui uma das técnicas mais utilizadas pelos pesquisadores que adotam a abordagem qualitativa, e, consiste na inserção do pesquisador no interior do grupo observado, tornando-se parte dele, interagindo por longos períodos com os sujeitos, buscando partilhar o seu cotidiano para sentir o que significa estar naquela situação. Através da OP foram efetivados registros fotográficos e anotações em diário de campo, possibilitando uma melhor reflexão e analise por parte dos pesquisadores para avaliação das contribuições das atividades empregadas no processo de ensino e aprendizagem dos estudantes.

O estudo foi realizado em uma escola pública, localizada na Cidade de Encanto, região do Alto Oeste, no Estado do Rio Grande do Norte, junto aos estudantes matriculados na $3^{\mathrm{a}}$ série do Ensino Médio, turnos matutino e vespertino, na qual cada turma era composta por 18 alunos. Foram utilizados os seguintes critérios para a participação da pesquisa: I - está devidamente matriculado na instituição, II - assiduidade nas aulas de química, incluindo concretização de atividades e discussões e III- assinatura do Termo de Consentimento Livre e Esclarecido (TCLE), visando à segurança do pesquisador e pesquisado. Visando proporcionar uma efetiva e satisfatória em funções orgânicas e suas relações com o meio ambiente, estruturou-se uma sequência didática em 05 etapas (Figura 1).

Figura 1 - Síntese das atividades desenvolvidas.

Sondagem dos conhecimentos prévios dos estudantes
Aula de campo ao Rio Encanto
Aulas expositivas-dialógicas (Química e meio ambiente)
$3^{\text {a }}$ ETAPA
Elaboração de cartazes educativos-ambietais
$4^{\text {a }}$ ETAPA
Socialização de cartazes educativos-ambietais
$\mathbf{5}^{\text {a }}$ ETAPA

Fonte: Dados da pesquisa. 
Para a efetivação das atividades, a turma foi dividida em três grupos, cada um com 06 componentes, denominados: Grupo I, Grupo II e Grupo III, estabelecidos pelos próprios alunos, elegendo um discente como representante de cada grupo. O aluno eleito pelo grupo, auxiliou os demais na condução das etapas, organizando e descrevendo as discussões realizadas a respeito do tema. Ressalta-se que as formações dos grupos com essas características permaneceram fixas e trabalharam juntos durante a SD.

$\mathrm{Na}$ primeira etapa foi realizada uma sondagem de conhecimentos prévios dos utilizando-se de uma questão problematizadora, contextualizando um tema sobre a "poluição de rios". As questões foram: "O rio da nossa cidade, rio Encanto, sofre com problemas de poluição?" "Como a poluição do rio afeta a constituição dos elementos químicos?”. Neste momento, os alunos foram orientados a refletir, dialogar e trabalhar em grupos. As discussões foram realizadas entre grupos, e as respostas apresentadas foram sintetizadas e registradas nas cartolinas de seu respectivo grupo e, em seguida, apresentadas ao grande grupo.

Na segunda etapa, houve uma aula de campo, na qual, os alunos foram levados para uma visita in loco ao rio da cidade, para registrarem as informações observadas (com anotações e fotografias) sobre os problemas encontrados no local. Como critério, estes problemas deveriam ter relação direta ou indireta com formas de poluição do rio. Na ocasião, foi entregue um roteiro previamente elaborado pelo docente, com o objetivo de auxiliar os alunos a detectarem os problemas ambientais de origem antropogênica.

$\mathrm{Na}$ terceira etapa foi realizada uma aula expositiva-dialogada para abordar os conteúdos funções orgânicas e seus grupos funcionais, com ênfase em propriedades, exemplos e aplicações práticas desses compostos no dia a dia. Para complementar, foi feita a leitura de um texto para potencializar os conceitos e alguns exemplos da química orgânica em nosso cotidiano, ressaltando a variação de compostos orgânicos e sua organização quanto ao grupo funcional característico.

Na quarta etapa, visando trabalhar as funções orgânicas, foi solicitada a elaboração de cartazes educativo-ambientais na escola relacionando os conceitos das funções orgânicas dos elementos químicos que causam problemas ambientais e que foram encontrados no rio da cidade, seja nas proximidades do ecossistema ou dentro do ecossistema. Na quinta etapa, houve um momento de socialização/exposição para a turma, escola e seus funcionários. Para realização deste momento, o educadorpesquisador organizou uma sala temática para que os alunos apresentassem à comunidade acadêmica.

\section{Resultados e Discussão}

Partindo da sondagem dos conhecimentos pôde-se explorar o tema qualidade da água para a manutenção da vida e sobrevivência dos seres vivos, questionando os alunos sobre os "possíveis impactos de uma alteração neste ambiente" e "como isso poderia afetar direta ou indiretamente o nosso cotidiano". No tocante a esse primeiro momento, os alunos apresentaram opiniões, hipóteses e posicionamentos correlacionado a problemática apresentada. Por meio das estratégias utilizadas, percebeuse o despertar da curiosidade dos alunos sobre o tema qualidade da água, o qual possibilitou a dialogicidade entre os alunos, propósito da educação problematizadora proposta por Freire (2011). Para Delizoicov, Angotti E Pernambuco (2011), o ponto culminante dessa problematização é fazer que o aluno sinta a necessidade da aquisição de outros conhecimentos que ainda não possui, ou seja, procura-se configurar a situação em discussão como um problema que precisa ser observado e enfrentado.

Por meio dessa etapa inicial, foram explicitados os diversos problemas socioambientais envolvendo o rio da cidade (doenças, alterações na água e suas implicações para consumo, mau cheiro, morte de animais, etc.) e uma tentativa de aproximação com conceitos químicos. Também foi observado, a integração entre os componentes, e ao mesmo tempo a necessidade de instiga-los a buscarem novos conhecimentos sobre o assunto. Conforme descrito por Moura-Figueira E Rocha (2016), os alunos possuem representações das realidades que são vivenciadas e construídas ao longo de sua vida de cada indivíduo e que os acompanham durante o seu desenvolvimento até os espaços acadêmicos (escolas, universidades). 
Em seguida, a aula de campo com visita in loco ao rio da cidade, tornou-se de grande relevância para corroborar com as discussões feitas anteriormente, possibilitando aos discentes detectarem os problemas ambientais de origem antropogênica identificando-os na realidade local (Figura 2). Cada grupo pôde associar as suas respostas (registradas na primeira etapa) em sala de aula com a realidade observada no rio da cidade, bem como puderam documentar seus achados através de registros escritos e fotográficos sobre os problemas ambientais encontrados durante a visita ao rio. O pesquisador e o docente regente da turma acompanharam todo o processo ao longo da visita.

Figura 2 - Visita ao rio da cidade.

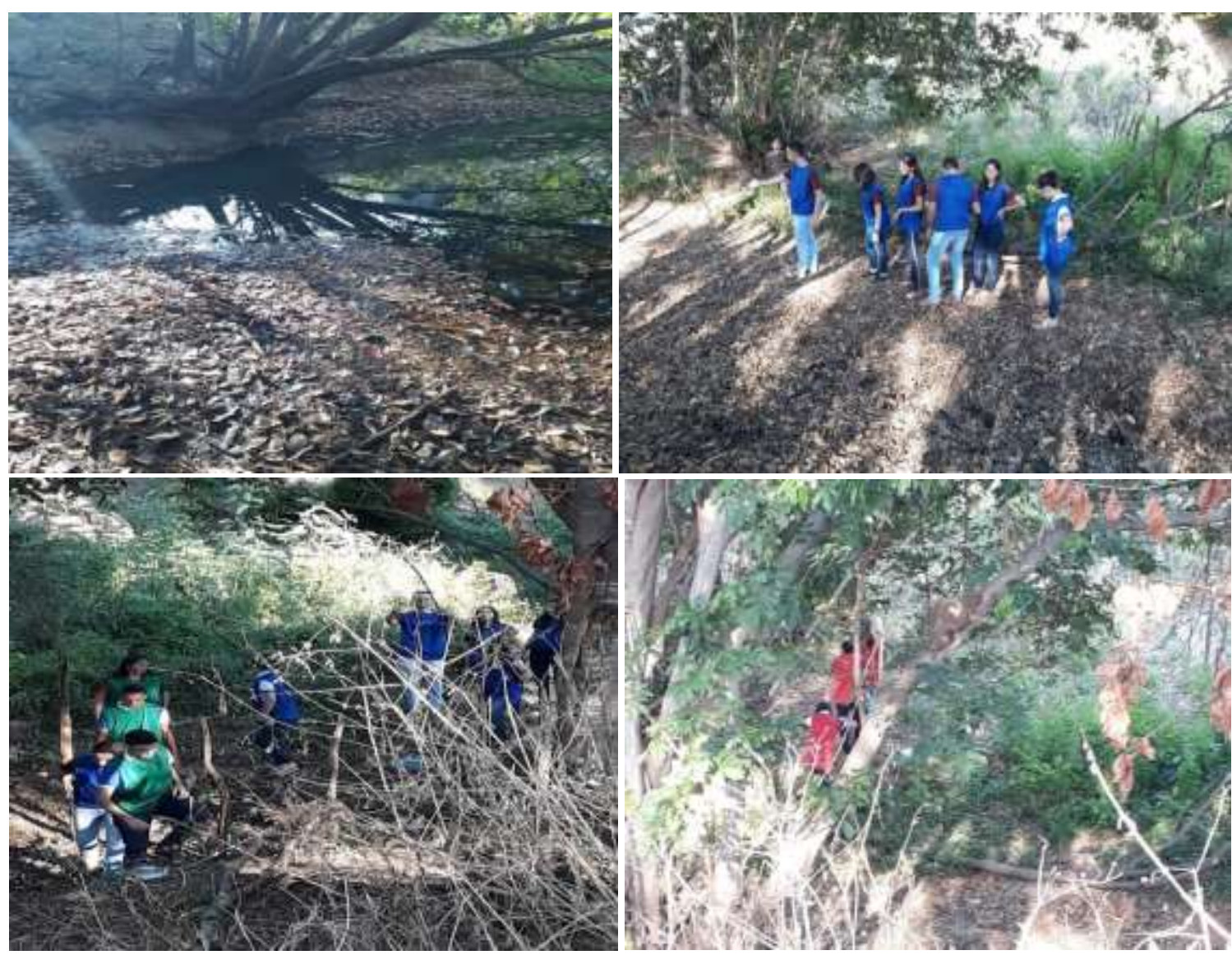

Fonte: Dados da pesquisa.

Segundo Morais e Paiva (2009) as aulas de campo são oportunidades em que os discentes poderão descobrir novos ambientes fora da sala de aula, incluindo a observação e o registro de imagens e/ou de entrevistas as quais poderão ser de grande valia. Sobre aspectos da aprendizagem em campo, Silva, Santos e Gertrudes (2014) afirmam que esse processo é capaz de transpor conhecimentos teóricos da aula para a realidade e proporcionar a ruptura da abstração dos conteúdos, bem como, estreitar as relações de companheirismo. As aulas de campo também oferecem a possibilidade de trabalhar de forma interdisciplinar, pois dependendo do conteúdo, podem-se abordar vários temas (Morais \& Paiva, 2009).

Durante as aulas dialógicas e rodas de conversas, conhecimentos sobre as funções orgânicas (Hidrocarbonetos, álcoois, fenóis, aldeídos, cetonas, ácidos carboxílicos, ésteres, éteres, nitrocompostos, etc.) e seus grupos funcionais puderam ser apreendidos e internalizados pelos estudantes, possibilitando a estes compreenderem as questões inicialmente trabalhadas na problematização inicial, relacionando o tema com a problemática do rio. Destaca-se que os discentes participaram ativamente das discussões realizadas em sala, sempre associando e comparando os conhecimentos anteriores e vivenciais. De acordo com Dias-da-Silva et al. (2017) as atividades envolvendo diálogos e discussões promovem o desenvolvimento cognitivo do aluno, 
bem como contribuem para a organização e, consequentemente, a aprendizagem dos conteúdos de ciências, que auxiliam os estudantes a lidar com as informações, compreendê-las e reelaborá-las, e assim compreender e interagir com o mundo e nele agir com autonomia.

Posteriormente, alunos produziram cartazes educativo-ambientais para exposição em sala temática, relacionando os conceitos de funções orgânicas com os problemas ambientais encontrados no rio da cidade. Os estudantes fizeram uso de vários recursos para a produção dos cartazes, entre eles as fotografias do momento da visita ao rio e de ilustrações temática da poluição do rio.

Figura 3 - Produção dos cartazes durante a aplicação do conhecimento.
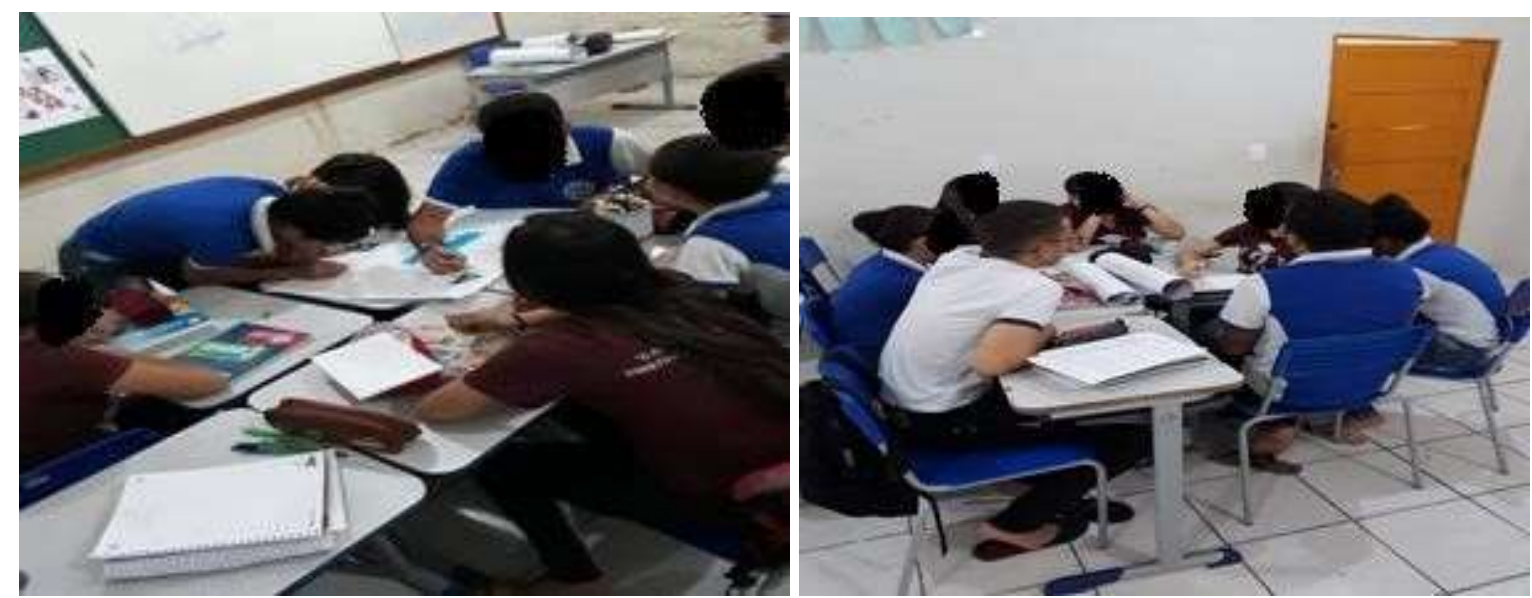

Fonte: Dados da pesquisa.

Após a construção e organização dos materiais elaborados, os alunos socializaram os cartazes para outros estudantes, docentes e servidores da escola, a fim de promover a conscientização com relação a poluição do rio, estabelecendo relação com os conteúdos químicos (Figura 4).

Figura 4 - Socialização dos cartazes durante a aplicação do conhecimento.

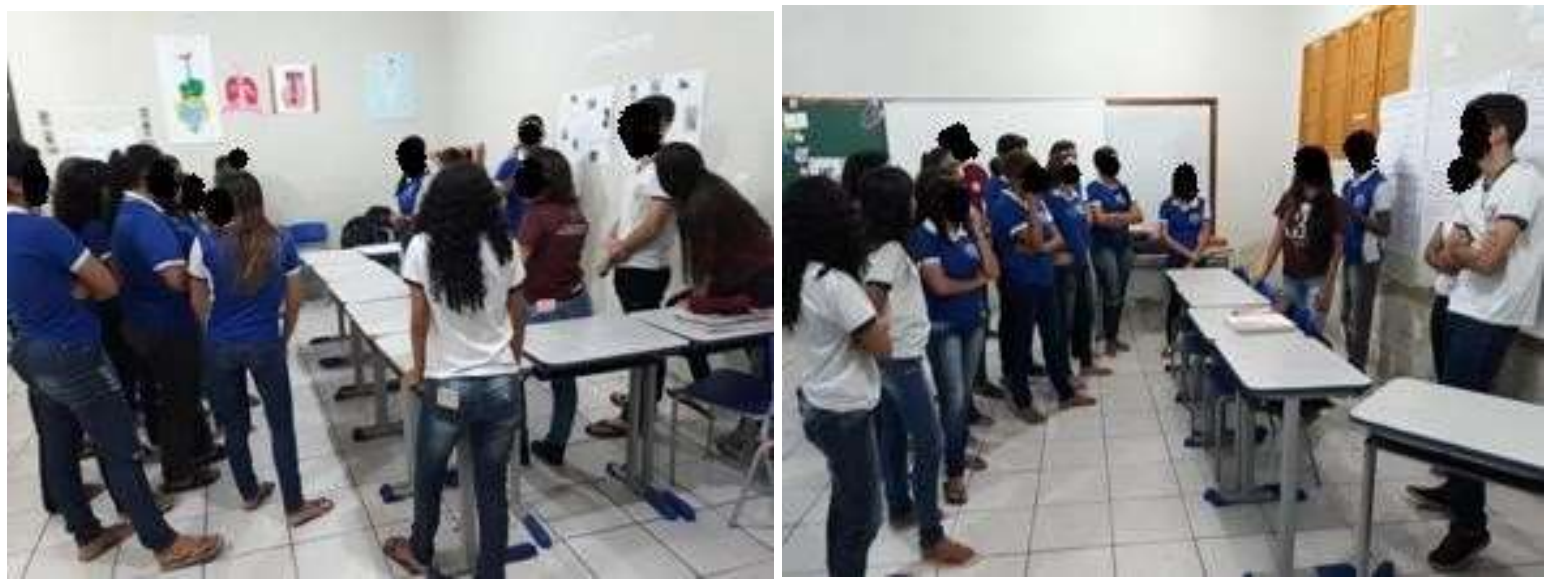

Fonte: Dados da pesquisa.

Para Veiga (2000) o ensino é socializado quando é centralizado na ação intelectual do aluno sobre o objeto da aprendizagem por meio de cooperação entre os grupos de trabalho, da diretividade do professor, não só com a finalidade de facilitar a aprendizagem, mas também para tornar o ensino mais crítico (explicitação das contradições) e criativo (expressão elaborada). Ela permite a troca de conhecimentos, estimulando o desenvolvimento do respeito de ideias, raciocínio crítico, 
questionamentos e soluções, favorecendo a troca de experiência, de informações, da cooperação e do respeito mútuo entre os alunos, possibilitando aprendizagem significativa (Dias-da-Silva, 2018).

No momento da socialização dos cartazes, foi possível identificar nas falas dos alunos a necessidade de ter conhecimento das funções orgânicas por estarem tão presentes em nosso cotidiano nos mais diversos materiais que utilizamos diariamente: "É importante ter conhecimento das funções orgânicas, pois elas estão muito presentes em nosso cotidiano e quando descartadas de forma errada elas são prejudiciais ao ambiente e ao próprio homem”. (Aluno 5). Pudemos observar também que, apesar de ser uma realidade a qual os alunos estavam inseridos, muitos não conseguiam associar os problemas e/ou tinham conhecimento da quantidade e gravidade da poluição presente no rio da própria cidade: "Eu, particularmente, não tinha noção que o nosso rio era tão poluído, que sofria com essa poluição causada por nós que somos os que mais precisamos dele". (Aluno 12). Neste sentido, concordamos com Alcântara (2015) no que a importância da associação de aulas com outras ferramentas e estratégias de ensino que auxiliem na motivação dos alunos para o processo de assimilação de conceitos teóricos, a reflexão e a análise de conteúdos/temas associados as questões ambientais.

Ficou evidenciado por meio das discussões realizadas em sala, bem como apresentadas aos visitantes da sala temática, que o rio da cidade sofre com problemas de poluição e que, na sua grande maioria, estão relacionadas com as funções orgânicas, porém poucos alunos conseguiam associá-las devida as ínfimas discussões relacionando temas da química orgânica com o meio ambiente e o cotidiano dos mesmos.

\section{Considerações Finais}

Por meio do relato efetivado, tona-se possível perceber o quanto que as atividades estruturadas dentro da SD aplicada, como por exemplo, uso de questões problematizadoras, aulas de campo, aulas expositiva-dialógica, elaboração e socialização de cartazes educativos-ambientais, são válidas e podem contribuir para o envolvimento dos estudantes com seu processo de aprendizagem, na medida em que estes participaram do processo de construção de conhecimento científico envolvendo um problema socioambiental ao qual estavam inseridos. Por meio desta experiência, acredita-se que a inserção de temas ambientais associadas às aulas de Química, possibilitam que os discentes sejam melhor sensibilizados quanto as questões ambientais locais, tornando-se assim cidadãos críticos e conscientes, que possam intervir no meio social de sua vivência com práticas socioambientais inovadoras, transformadoras e sustentáveis.

\section{Referências}

Alcântara, V. (2015). Importância das atividades de campo no ensino da geografia e na educação ambiental no desenvolvimento consciência crítica do aluno. Anais do Uso Público em Unidades de Conservação, 3(7), 85-92.

Angrosino, M. V. (2009). Etnografia e observação participante. Artmed.

Arrigo, V., Alexandre, M. C. L., \& de Souza Assai, N. D. (2018). O ensino de química e a educação ambiental: uma proposta para trabalhar conteúdos de pilhas e baterias. Experiências em Ensino de Ciências, 13(5), 306-325.

Brasil (2013). Diretrizes Curriculares Nacionais para Educação Básica. http://portal.mec.gov.br/docman/julho-2013-pdf/13677-diretrizes-educacao-basica2013-pdf/file. Acesso em: 02 set. 2019.

Brasil. (2006). Ministério da Educação. Secretaria de Educação Básica. Orientações Curriculares para o Ensino Médio. MEC, $2,135$.

Castro, E. A., Paiva, F. M., \& Silva, A. M. (2019). Aprendizagem Em Química: Desafios Na Educação Básica. Revista Nova Paideia-Revista Interdisciplinar em Educação e Pesquisa, 1(1), 73-88.

Delizoicov, D., Angotti, J. A., \& Pernambuco, M. M. C. A. (2002). Ensino de Ciências: fundamentos e métodos. (4a ed.), Cortez.

Dias-da-Silva, C. D. et al. (2018). Abordando o sistema respiratório em uma perspectiva dos três momentos pedagógicos. CARPE DIEM: Revista Cultural e Científica do UNIFACEX, 16(1), 29-43.

Dias-da-Silva, C. D. et al. (2016). Aprendendo sobre o corpo humano: contribuições do pibid para o ensino de ciêncas. CARPE DIEM: Revista Cultural e Científica do UNIFACEX, 14(1 esp.), 17-30. 
Research, Society and Development, v. 10, n. 8, e25110817378, 2021

(CC BY 4.0) | ISSN 2525-3409 | DOI: http://dx.doi.org/10.33448/rsd-v10i8.17378

Diniz, F. E. et al. (2020). Análise das concepções alternativas dos estudantes de Ensino Médio sobre as funções orgânicas e suas relações com o meio ambiente. Revista Brasileira de Educação Básica, 5(16), 1-13.

Diniz, F. E. et al. (2021). A abordagem dos três momentos pedagógicos: aplicação no estudo de funções orgânicas e meio ambiente. Retratos da Escola, 15(31), $241-261$.

Freire, P. (2014). Pedagogia do oprimido. (57a ed.), Paz e terra.

Galvão, E. C. (2013) O compromisso formativo na avaliação da aprendizagem em química: das concepções às abordagens do erro. 2013.113 f. Dissertação (Mestrado em Educação), Universidade Estadual de Londrina, Londrina.

Gil, A. C. (2002). Como elaborar projetos de pesquisa. Atlas.

Hoffmann, J. (2011). Avaliação Mediadora. (31a ed.), Mediação.

Latini, R. M., \& da Conceição Sousa, A. (2016). Ensino de Química e Ambiente: as articulações Presentes na Revista Química Nova na Escola (QNEsc). Investigações em Ensino de Ciências, 16(1), 143-159.

Lima, T. O., dos Santos, A. N., da Silva, M. J., \& de Menezes Guedes, M. G. (2019). Uma vivência fundamentada nos três momentos pedagógicos no ensino de funções orgânicas. Revista Vivências em Ensino de Ciências, 14(1), 14-26.

Lopes, R. M. et al. (2011). Aprendizagem baseada em problemas: uma experiência no ensino de química toxicológica. Química Nova, 34(7), 1275-1280.

Méheut, M. (2005). Teaching-learning sequences tools for learning and/or research. Springer.

Morais, M. B.; Paiva, M. H. A. (2009). Ciências - ensinar e aprender. Dimensão.

Morais, C. S., \& Ferreira, H. S. (2016). A Educação Não-Formal para a Promoção da Cultura Científica e Tecnológica no Ensino de Química e das Ciências. Revista debates em ensino de química, 2(2), 45-55.

Figueira, A. C. M., \& Rocha, J. B. T. D. (2016). Concepções sobre proteínas, açúcares e gorduras: uma investigação com estudantes de ensino básico e superior. Revista Ciências \& Ideias [recurso eletrônico]. Nilópolis, RJ. Vol. 7, n. 1 (2016), p. 23-34.

Nascimento, T.; Ricarte, M. J.; Ribeiro, S. M. (2007). Repensando o Ensino de Química a Nível Médio. In: Congresso Brasileiro de Química, 47. Anais... Natal: CBQ.

Oliveira, M. M. (2016). Como fazer pesquisa qualitativa. (7a ed.), Vozes.

Pazinato, M. S., \& Braibante, M. E. F. (2014). Oficina temática composição química dos alimentos: uma possibilidade para o ensino de química. Química Nova na escola, 36(4), 289-296.

Queiroz, D. T., Vall, J., Souza, Â. M. A., \& Vieira, N. F. C. (2007). Observação participante na pesquisa qualitativa: conceitos e aplicações na área da saúde. Rev. enferm. UERJ, 276-283.

Rodrigues, J. C. et al. (2018). Elaboração e aplicação de uma Sequência Didática sobre A Química dos Cosméticos. Experiências em Ensino de Ciências, 13(1), 211-224.

Santos, D. B. (Org)(2020). Ações Educativas na Prática Ambiental: perspectivas teóricas e práticas. EDUERN.

Santos, W. L. P. (2011). A Química e a formação para a cidadania. Educación química, 22(4), 300-305.

Santos, P. T. A. et al. (2011). Lixo e reciclagem como tema motivador no ensino de química. Eclética Química, 36(1), 78-92.

Silva, L. M., Santos, V. V., \& Gertrudes, F. A. L. (2015). Biologia na aula de campo: reconhecendo a interdisciplinaridade através da visita ao Geopark Araripe. Revista Sapiência: sociedade, saberes e práticas educacionais, 3(2), 143-157.

Silva, M. D. et al. (2015). Compostagem: experimentação problematizadora e recurso interdisciplinar no ensino de química. Química Nova na Escola, 37(1), 71-81.

Veiga, I. M. A. (2000). Técnicas de ensino: Por que não? Papirus.

Wartha, E. J., \& Faljoni-Alário, A. (2005). A contextualização no ensino de química através do livro didático. Química Nova na Escola, 22 (2), $42-47$.

Zabala, A. (1998). A Prática Pedagógica: como ensinar. Artmed. 